Berkeley Law

From the SelectedWorks of Robert Cooter

June, 1987

\title{
Justice at the Confluence of Law and Economics
}

Robert D. Cooter 


\title{
Justice at the Confluence of Law and Economics
}

\author{
Robert Cooter ${ }^{1}$
}

\begin{abstract}
Law has long been combined with economic thought, but only recently has law been combined with economic theory. This article explores the implications of this development for theories of justice and interdisciplinary research. Value in economics is usually measured by price (the market tradition) or by satisfaction (the utilitarian tradition). The relationship of these concepts to equity in law is explored. Also explored is the relationship between bargaining theory and contractarian theories of justice. The article examines the possibility that methods and concepts developed in the economic analysis of law will prove useful to sociologists and social psychologists by contrasting the study of rational choice and the study of attitudes.
\end{abstract}

KEY WORDS: equity; efficiency; interdisciplinary research.

\section{INTRODUCTION}

As a boy I camped on a sandbar off the Carolina coast at the confluence of two ocean currents that made the waters rough but fertile. As an economist in a law school, I am at the confluence of two intellectual traditions. The contrast in methods between economics and law is stark - one is quantitative, the other is verbal; one is empirical, the other is hermeneutical; one aspires to be scientific, the other aspires to be just. Given these differences, discourse between economists and lawyers is inevitably rough, but it has also been fertile in recent years.

Law has long been combined with economic thought, which is informal and discursive, but law's combination with economic theory, which is mathematical and analytical, is recent. ${ }^{2}$ About 25 years ago economic theory

'School of Law, University of California, Berkeley, California 94720.

${ }^{2}$ The distinction between economic thought and economic theory was made by Schumpeter, 1967. 
broke through the confines of antitrust law and began spreading into the common-law subjects that are central to Anglo-American legal education (Coase, 1960). Now the major American law schools have at least one pure economist on thier faculty, and economic analysis has worked its way into the teaching of the core subjects in the first year of law school. Like the rabbit in Australia, economics is quickly filling a vacant niche in the intellectual ecology - the absence of mathematical theory and statistical methods in law.

This article explores the implications of these events for theories of justice and interdisciplinary research. Economics is called the "Queen of the Social Sciences," not only because of its power but because of its imperialism - it seems bent on conquest rather than cooperation with other social theories. (Tom Schelling reported that when he surveyed the staff at the Rand Corporation, the economists claimed to benefit from interacting only with mathematicians, not with other social scientists.) This bristling stance has infected the economic analysis of law. Indeed, some proponents argue that the fundamental normative concept in economics, efficiency, should displace the fundamental normative concept in law, justice. ${ }^{3}$ An alternative view, developed in this article, is that economic concepts should elucidate, not displace, legal concepts of justice. Similarly, economic theory can elucidate many issues in sociology and social psychology. There are, however, structural differences that obstruct the integration of economics with other social theories. The conclusion of this article identifies some of these obstracle and speculate about the future of cross-disciplinary research on justice.

\section{JUSTICE IN ECONOMIC THEORY}

In economics, the term allocation pertains to the efficient use of resources, and the term distribution pertains to the fair division of wealth among classes and groups. This essay follows economic usage in applying these terms, which is not always consistent with usage in law or social psychology. Some economists, such as those who estimate the demand and supply of goods, conceive of themselves as studying allocation but not distribution. Other economists, who work in such areas as taxation or cost-benefit analysis, which are closely tied to public policy, cannot dismiss the problem of distribution

${ }^{3}$ This is a theme running through Posner's work, 1973, 1983, 1986. Posner has also argued uncompromisingly that economics is a positive science in which concepts of justice have no place. 
so easily. But in all branches of contemporary economics, the dominant normative concept is efficiency, not distribution. To illustrate, even in the tax area where questions of distribution arise forcefully, most of the economics literature concerns efficiency, specifically the problem of raising revenue by means that impose the smallest possible burden on the economy. Less prominent than efficiency in this literature are the several concepts of tax equity in the economics tradition. (See, for example, Musgrave and Peacock, 1967.)

For some economists, efficiency is not merely a more prominent concept than justice, but in addition they regard justice and other social values with contempt. This hostility was rationalized and systematized by an intellectual development called "ordinalism" that began in the 1930s and culminated in the 1950s. (A recent history is found in Cooter and Rappoport, 1984.) The ordinalists attempted to separate the hard, scientific core of economics from its soft periphery. Concepts in the periphery, including philosophical concepts like justice that are drawn from a 2000 -year-old tradition, were lumped together as nonscience, and, like other social theorists who sought to demystify the world, economists often dismissed nonscience as little more than nonsense. ${ }^{4}$ Fortunately, the attempt to quarantine social values and eradicate them from economics has lost its vigor. It seems that questions of distributive justice will persist as a significant but secondary part of the subject.

This prognosis for theories of justice must be tempered by the observation that, upon scrutiny, the concepts of justice used in economics often resemble efficiency. Indeed, at a mathematical level, it seems that the dispute about justice among economists is really a dispute about how broadly to interpret efficiency. The explanation of this curious fact is found in the structure of utilitarian thought, which requires a detailed explanation.

\section{Utility and Justice}

Economics acquired its contemporary mathematical form in the last quarter of the 19th century when Bentham's utilitarian philosophy was com-

\footnotetext{
${ }^{4} \mathrm{~A}$ wide-ranging philosophical attack upon nonscientific concepts was part of the program of the logical positivists. Their view, in its starkest form, was that propositions with no predictive consequences cannot be proved true or false, even in principle, so these propositions must not have any meaning. This line of thought was summed up in the last sentence of Wittgenstein's (1967) Tractatus Logico-Philosophicus: "What we cannot speak about we must pass over in silence." The ordinalists in economics, apparently under the influence of the logical positivists, insisted that economists qua economists have nothing to say about justice.
} 
bined with Newton's calculus (Blaugh, 1979). The central insight was that a utility maximizing consumer would equate the price of each good to its marginal utility (Jevons, 1871/1911). Bentham (1973) described utility as a quantity that could be added up for different people like body weight. Unlike body weight, however, more utility is regarded as socially better: "The interest of the community then is, what? - the sum of the interests of the several members who compose it" (Bentham, 1973). Any legislation or moral norm that increases the sum of individual utilities is a social improvement by this standard.

Several approaches to distributive justice coexist in economics but the strongest tradition is utilitarianism. The concept of utilitarian justice is that one person's pleasure counts as much as another's. Thinking that one person's pleasure could count more than another's - say, more weight should be given to the pleasures of patricians than plebeians, or more weight should be given white people than black people - is a misunderstanding of the metric, rather like thinking that a pound of lead weighs more than a pound of feathers. In Bentham's theory, pleasure receives the same weight regardless of who enjoys it. Each person's utility receives equal weight in computing the sum that society should maximize, and therein lies utilitarian justice.

When this theory is applied to the distribution of wealth, the result can be egalitarian or antiegalitarian, depending upon other considerations. The first consideration is the relationship between utility and wealth. Most economists working in the utilitarian tradition assume that increases in a person's wealth cause utility to increase at a decreasing rate. Thus the utility gained from giving an additional dollar to a rich person is less than would be gained from giving the dollar to a poor person. In technical terms, the standard assumption is that the marginal utility of income declines with wealth (Pigou, 1920).

The consequences for public policy can be illustrated by two practical examples. First, consider the theory of optimal income taxation. According to the usual models, an increase in tax rates discourages work and investment. Consequently, the higher the levels of taxation, the less wealth will be produced by society. However, redistributive taxation transfers wealth from the rich, whose marginal utility of income is low, to the poor, whose marginal utility of income is high. If the discouraging effects of taxation on work and investment are not too great, and if the marginal utility of income is substantially higher for the poor than for the rich, the sum of utilities for society will be greatest when there is redistributive taxation. ${ }^{5}$

${ }^{5}$ Fresh life was breathed into this line of thought by the introduction of control theory. The original paper was by Mirrlees, 1971. For a summary of results, see Cooter, 1978. 
As a second example, consider cost-benefit analysis as applied to public sector investment. Government investment projects yield a stream of benefits and costs that fall upon different classes of people. These benefits and costs have a market value, but the market value is different from the social value as measured by utilitarian theory. The utilitarian approach would apply different weights to the market value of the benefits and costs, depending upon the wealth of the affected class. To illustrate, an investment that yielded improved housing to the poor would receive extra weight because its social value allegedly exceeds its market value. The excess of social value over market value is due to the fact that the marginal utility of income for the poor presumably exceeds the marginal utility of income for the average consumer.

An alternative to the utilitarian tradition is to proceed on the basis of market values alone. To appreciate the difference in approaches, consider what happens when market values are used in the preceding examples. The tax example assumed that taxation discourages investment and work, so the market value of the goods produced by the economy will be reduced as a consequence of redistributive taxation. The implication is that redistributive taxation undermines the policy goal of maximizing the market value of the good and services produced by the economy. Similarly, using market values in cost-benefit analysis causes the decision makers to ignore the distributive considerations that favor low-income housing.

Earlier I suggested that when economists argue about justice they are usully arguing about how broadly to interpret efficiency. The contrast between utilitarian values and market values illustrates this point. The utilitarian theory takes the view that the marginal utility of income declines with wealth, and, consequently, utilitarians favor income redistribution in order to maximize the sum of utilities. The alternative approach in economics, sometimes called the efficiency approach, takes the view that markets measure value and, consequently, the efficiency approach opposes redistribution whenever it reduces the total wealth of society. The difference in approaches is whether social value is measured in utils or wealth. The only role of individuals and classes in both approaches is to contribute to the sum of social value. Philosophers have argued eloquently that an adequate theory of justice must regard individuals and classes as more than producers of wealth or utility. From the perspective of these philosophies, both approaches are based upon . efficiency-utilitarian efficiency or market efficiency.

\section{Individual Utility and Social Utility}

In the utilitarian tradition, the utility of different people is added together and the size of the sum is used to guide public policy. In contrast, 
the concept of utility used to explain market behavior does not require adding the utilities of different people. Thus the analysis of markets draws upon a concept of individual utility and public policy analysis draws upon a concept of social utility. The ordinalists who want economics confined to its scientific core accept the use of individual utility but reject reasoning based upon social utility.

To appreciate the difference between individual utility and social utility, a technical explanation must be understood. A rational individual can rank alternative bundles of commodities from bad to good according to his preferences. Similarly, the real numbers can be ranked from small to large. Since goodness and real numbers are both ordered, they can be associated with each other. Real numbers can be assigned to commodity bundles, with the higher numbers being associated with the more preferred bundles, as shown in Fig. 1 for three commodity bundles. This association of bundles with numbers is what contemporary economists mean by the term "utility function." A utility function gives numerical values to the ordering of goods. Economics thus relies upon a theory of value that is based upon the real number system.

The choice of numbers in the preceding association is arbitrary in the sense that many different utility functions could be used to represent the same ordering of commodity bundles. In psychological jargon, the scale represented by the utility function is not anchored. To illustrate, in the preceding representation, the bundles $(A, B, C)$ are associated with the numbers $(0$, 10,40 ). The fact that $C$ is better than $B$, and $B$ is better than $A$, is represented

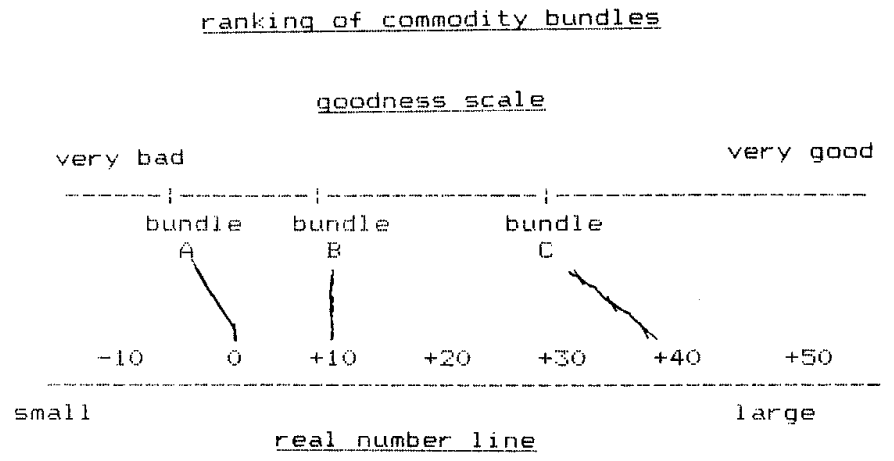

Fig. 1. Ranking of commodity bundles from good to bad, using a real number system. 
by the fact that 40 is larger than 10 , and 10 is larger than 0 . However, the same information could be expressed by associating $(A, B, C)$ with $(10,20$, 30 ). The only feature of the real numbers that is important is their order, not their absolute size. Consequently, a utility function expresses values as a ranking of alternatives.

The contrast between individual utility and social utility can be explained in terms of utility functions. If an economist knows an individual's orderings of commodity bundles, that person's market behavior can be predicted. No more information is needed about the individual's value system. However, if social choices are to be made in which the interest of one person is traded off against the interests of others, more is required than a knowledge of the preferences of individuals. (This fact is also discussed in Hardin, 1986, in this volume.) To illustrate, Bentham thought that social choices should be made by adding up the utilities of different people. It makes a big difference to the sum of utilities whether the utility a person derives from bundle $A$ is 0 utils or 10 utils. In order to add up utilities, the utility numbers must be anchored. Anchoring the scale requires going beyond the ordinalist concept of value.

Unanchored individual utilities suffice to explain markets, but anchored social utilities are needed to guide policy. There are, however, limitations to the usefulness of social utilities in public policy decisions that are expressed in a powerful critique of utilitarianism developed by contemporary philosophers (Rawls, 1971; Dworkin, 1977). The critique is based upon a contrast between individual utility and social utility. The economic theory of individual utility relies upon the idea that rational people can rank states of the world from bad to good, and that they will try to obtain the best state that is feasible within the constraints under which they choose. Similarly, the utilitarian theory of social choice relies upon the idea that rational officials can rank public policies from bad to good, and that they will choose the best policy that is feasible. Thus the utilitarian tradition treats a society of many people as if it were a single rational person. The critics contend that so long as society is treated as a single rational person, the differences between individuals and groups are inadequately represented and the theory cannot produce a satisfactory account of justice. Thus, a theme in Rawls's Theory of Justice is that utilitarianism does not take differences among persons seriously.

\section{The Impossibility of a Social Welfare Function}

As explained, the utility function of an individual is a mathematical expression of his preference ordering over commodity bundles. Just as the 
individual has a preference ordering over commodities, so it is possible to imagine that society has a preference ordering over public policies. Social preferences can be expressed mathematically just like individual preferences: Larger numbers can be assigned to socially preferred states. The function that assigns numbers to public policies according to social preferences is called a "social welfare function" (Bergson, 1938). A social welfare function is an ordering of public policies by society, just like a utility function is an ordering of commodity bundles by an individual.

Bentham's (1973) sum of individual utilities is a particular form of a social welfare function, specifically an additive form. Other forms are possible - for example, instead of adding individual utilities, they could be multiplied. In any event, the crucial step in constructing a social welfare function is to find a way to anchor the utilities of individuals. Anchoring individual utilities so as to construct a social welfare function is the economist's way of describing the fundamental task of political philosophy and ethics.

By casting traditional problems of political philosophy in this novel language, economists brought them into contact with mathematics and, as it turns out, mathematics revealed formidable obstacles to any measure of social utility. For example, economists found that majority rule often has circular outcomes. It is easy to construct examples in which policy B wins a majority against policy $\mathrm{A}$, policy $\mathrm{C}$ wins a majority against policy $\mathrm{B}$, and, finally, policy A wins a majority against policy $\mathrm{C}$, so that majority voting runes in the following circle:

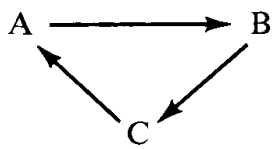

When majority rule runs in a circle, it does not indicate how policy makers should choose among the alternatives. ${ }^{6}$

A social welfare function is a ranking of policy alternatives. The failure of majority rule to rank alternatives implies, in economic jargon, that it does not "induce a social welfare function." Arrow (1951) generalized the paradox of majority rule and demonstrated a stunning conflict between political and economic values. Verbal statements of his mathematical results are inevitably facile, so the scrupulous reader must puzzle through Arrow's proof to appreciate it. (The easiest exposition is given by Sen, 1970.) What he proved, approximately, is that it is impossible to construct a political constitution that is both democratic and efficient in all the choice situations that the society might face (see Arrow, 1951). The constitution must fall short on one of

${ }^{6}$ Suppose there are three voters. Voter I's preferences are $\mathrm{C}>\mathrm{B}>\mathrm{A}$. Voter II's preferences are $\mathrm{A}>\mathrm{C}>\mathrm{B}$. Voter III's preferences are $\mathrm{B}>\mathrm{A}>\mathrm{C}$. In a majority vote, then, $\mathrm{B}$ beats $\mathrm{A}, \mathrm{C}$ beats $\mathrm{B}$, and $\mathrm{A}$ beats $\mathrm{C}$. Check it for yourself. 
these values. An inefficient constitution in Arrow's theorem is one that could be modified to make at least one person better off without making anyone else worse off. (This is the definition of Pareto efficiency.) A dictatorial constitution in Arrow's theorem is one in which the choices over public policies necessarily correspond to the preferences of one person, who is the dictator.

The conclusion to be drawn is that any democratic constitution yields inefficient choices over some alternatives. This result comes as no surprise to anyone who has loitered in the halls of Congress, but it is deeply troubling to social theorists in the utilitarian tradition.

\section{Economics and Philosophy}

Arrow's theorem was the first of several impossibility proofs that stand in the way of introducing social values into economic theory. Any attempt to use economics to develop concepts of social justice must sooner or later confront these impossibility results. I believe the impossibility theorems pose more of a problem for practical politics than for ethics or political philosophy. Although I cannot defend this view in detail in this article, I suggest its basis by considering some developments in economic thinking about justice.

Until recently most disputes about justice among economists were disputes about how broadly to interpret effeciency. A more promising trend, which is quite recent, is a rapprochement between economics and political philosophy. Economics is now being used to develop traditions in political theory more rigorously than in the past. These developments are too broad to survey adequately in this brief article, but I can communicate their flavor.

There are, I believe, two fundamental mathematical concepts in economics: maximization and equilibrium. The idea of a maximum is the central idea in the utilitarian tradition. One of the most promising developments in economic philosophy is to develop a political philosophy based, not upon maximization, but upon the second fundamental idea, equilibrium. This is the recent thrust of contractarians, who regard political life as the outcome of a social bargain. The social contract, like a business contract, can be described as the equilibrium in a bargaining game among rational players. The contractarian tradition can thus be given a rigorous foundation in the economic theory of bargaining games.

A sense of how to proceed can be gained by contrasting several forms of contractarianism. There are, for example, contrasting traditions based upon Hobbes, Locke, and Rousseau. Hobbes took the view that the social contract arises from a state of nature in which rapacious individuals are unconstrained. In terms of bargaining theory, Hobbes' social contract was constructed as an alternative to the worst imaginable threats. Locke, on the other hand, described the state of nature as a condition in which moral norms are 
recognized but imperfectly enforced. In terms of bargaining theory, Locke's social contract was constructed as an alternative to the private enforcement of moral norms. Finally, a third theory of contract was provided by Rousseau. In his view, the social contract expressed the will of people who are not blinded by special interests and inherited privileges, so their manner of bargaining with each other to form the social contract is purged of the selfish consideration that permeate ordinary business dealings. These three philosophical traditions can, thus, be contrasted as bargaining games with different rules concerning the types of threats the parties can make against each other. (An explicit comparison of these three theories in terms of the economic theory of bargaining games is developed by Cooter (1983).)

These three traditions have been revived in recent years and embodied in major books. The Hobbesian tradition was embodied in James Buchanan's The Limits of Liberty; a version of Locke's theory was represented by Nozick's Anarchy, State, and Utopia; and a theory encompassing many features of Rousseau's philosophy was presented by Rawls (1971) in $A$ Theory of Justice. At the center of the logical structure of each of these books is the concept of bargaining equilibrium.

These examples demonstrate my general point that economics has within it the analytical resources to explicate traditions in political theory. These traditions have autonomy from utilitarianism and validity in spite of the impossibility theorems. My expectation is that economics will continue to be used to refine the great traditions of thought about justice in political philosophy and ethics.

\section{JUSTICE AND THE LAW FROM AN ECONOMIC PERSPECTIVE}

The practical problem of justice raised by a lawsuit is to resolve the dispute in a way that is fair to the parties. One aspect of courtroom fairness is legality - the idea that cases should be decided by the application of consistent rules that are reasonably interpreted. But legality is a formal aspect of justice, and an adequate theory must be substantive. There are approximately as many substantive theories of legal justice as there are ethical theories - utilitarian, Kantian, Aristotelian, etc. Attempting a summary of these theories in this article is hopeless. Instead, I explain how the economic analysis of law has affected legal thinking about justice, including the reevaluation of these older traditions.

In one of the great metaphors of social theory, Adam Smith stated that the participants in markets serve the public as if guided by a hidden hand. Economists have asserted that courts decide common-law disputes according to principles of economic efficiency as if guided by a hidden hand. Market 
efficiency is seldom the explicit aim of courts - their aim is more typically to reach a just resolution to the dispute - yet the economic analysis of law has shown a surprising correspondence between common-law rules and the efficient allocation of legal entitlements. If judges explicitly follow principles of justice and implicitly follow economic principles, so that the two types of principles track each other in many common-law disputes, market efficiency must be the content of common-law justice.

To appreciate this claim, it is helpful to explain what market efficiency usually means in a legal dispute. If one person values a car more than another, there is scope for a mutually beneficial exchange. Efficiency requires exchange to proceed until the owner of each good, including a car, values it at least as much as anyone else. Whenever the owner of a good values it less than someone else, exchange has not yet proceeded to the point where the pattern of ownership is efficient. When a state is reached in which the owner of each good values it at least as much as anyone else, the scope for mutually beneficial exchange is exhausted and the allocation of goods is efficient.

These propositions about goods also apply to legal entitlements. Efficiency requires the allocation of legal entitlements to the parties who value them the most. To illustrate, consider the entitlement to compensation for harm caused by accidents. The potential victims would be willing to pay a sum of money to secure this right. Similarly, the potential injurers would be willing to pay a sum of money to escape the duty to compensate. Efficiency requires the entitlement to be allocated to injurers or victims, depending upon which one values it more. If potential victims value the right to compensation more than potential injurers value freedom from liability, then the law should require injurers to compensate victims of tortious accidents. On the other hand, if the potential injurers would pay more to escape liability than the potential victims would pay for the right to compensation, then the law should not require injurers to compensate the victims of tortious accidents.

This example is stark, even shocking, yet its harshest critics must admit that market efficiency works better in explaining torts and other branches of the common law than anyone would have anticipated 25 years ago when the economic analysis of law was just beginning. (See for example Shavell, 1987, or see the torts chapters by Cooter and Ulen, forthcoming.) Assume for the sake of argument that market efficiency often explains common-law adjudication. This presumptive fact poses a puzzle to traditional theories of justice: Why is efficiency the substance of justice in these cases?

Many different answers can be given. One way is to argue that maximizing wealth is such an important social goal that it becomes embodied in social norms. (The view that the law should maximize society's wealth is 
defended by Posner, 1983.) I prefer arguments that are less materialistic in their foundation. Here is an example. Equal concern and respect for others is a fundamental moral value. A person who can avoid the risk of harming others at little expense to himself but fails to do so, treats others with contempt. In many contexts, equal concern and respect for others demands that we give similar weight to the benefits our actions create for them as to the costs they impose upon us. For example, we ought to take precautions against accidents whenever the cost of the precautions to us is less than the value of the reduction in risk for others. But this is exactly what efficiency requires with respect to precaution against tortious accidents. Both economic efficiency and the principle of equal concern and respect require that, in the context of tortious accidents, we give equal weight to our costs of precaution and to the resulting benefits to others.

The economic analysis of law is a consistent theory that applies to a wide range of legal phenomena. Future jurisprudence will have to come to terms with this fact. I have suggested one way of coming to terms, specifically by showing the convergence of efficiency and some moral values like equal concern and respect. Better ways may be found, but whatever else the future brings, the economic analysis of law is sure to remain controversial and influential.

\section{CONCLUSION: POSSIBILITIES FOR CROSS-DISCIPLINARY RESEARCH}

I have shown the fertility of the confluence of law and economics. What about the confluence of economics with sociology and social psychology? If economics is brought into contact with the study of justice by sociologists and social psychologists, will the confluence be as fertile as with law?

To answer this question, consider some structural similarities and differences. One reason for the success of the economic analysis of law is the similarity in the models of man at the core of the two subjects. The "rational man" in economics and the "reasonable person" in law are intimately related. Both assume that people are capable of obtaining information, processing it, and making thoughtful decisions. Some legal standards can be explained in terms of economic rationality. To illustrate, if an American law court reviews the policy of a regulatory agency and finds that it is irrational, the court will also conclude that the policy is unlawful. The similarities between rationality in economics and reasonableness in law provide a natural fit between the subjects, in spite of some salient differences.?

${ }^{7}$ To illustrate a significant difference, in economics a rational person is often assumed to be utterly selfish. Whether an economically rational man focuses exclusively upon, say, increasing his own wealth, or whether he treats others with equal consideration, is a matter of "in- 
In contrast to economics and law, psychology delights in holding up a mirror to human irrationality. Unreasonable behavior occupies a special place within this intellectual tradition. A major focus of psychological investigation is attitudes, which mingle preferences and beliefs in ways that need not conform to an economic standard of rationality. An obstacle to integrating the subjects is that the model of man that psychologists use to study attitudes does not assume rationality or reasonableness.

Another obstacle concerns the deductive structure of theory in economics. Most economic models assume that decision makers pursue objectives ("tastes") subject to constraints ("technology" and "resources"). Thus, in economic models, complex institutions such as markets, corporations, legislatures, and courts, are analyzed into the simple components of technology, taste, and resources. These simple components are the "givens," or the exogenous variables, in light of which everything else is explained. The pattern of explanation is to analyze complex entities into different combinations of simple elements, rather like chemicals are analyzed into different combinations of the elements in the periodic table.

Other social sciences have tried to create theories with some resemblance to atomic structure, but none have succeeded to the same extent as in economics. (For example, Marxists distinguish the base of society, consisting of the social relations of production, from the superstructure, consisting of everything else.) Furthermore, some theories in sociology and social psychology are like a merry-go-round in that it does not matter where one jumps on. To illustrate, structural-functionalists conceive of society as roles that are organized into interdependent institutions and filled by individuals. Interdependence consists in the fact that each institution supports and sustains the others by performing some necessary task for society, rather like the different stages on an assembly line combine to produce a valuable product. When embodied in a cybernetic model, the circular movement of such a theory is depicted by a series of feedback loops. Institutions are thus conceived to be functionally interdependent in such a way that they cannot be sorted into fundamental and derivative types. Instead of a vertical analysis that dissolves institutions into atoms, structural-functionalism proceeds horizontally by showing that one complex institution depends upon another. The interdependence constitutes a type of logical circularity but not a vicious circularity.

To illustrate the obstacles to combining an atomic theory like economics with a circular theory like structural-functionalism, consider the problem of

dividual preferences." In contrast, the "reasonable man" in legal thought scrupulously conforms to standards of social responsibility. Selfish behavior that harms others in ways violating social norms is considered unreasonable. It seems, then, that the reasonable man is the rational man with a particular set of preferences, specifically the preferences of a perfectly socialized person. 
the acquisition of tastes. Taste is an expansive term applied by economists to such disparate mental furnishings as values, needs, attitudes, and wants. Other social sciences try to explain tastes. For example, developmental psychology concerns the acquisition of personality, and sociology analyzes the reproduction of society, which occurs by fitting the young into the roles currently performed by their elders. In contrast, there is no body of economic theory concerned with the development of personality and the reproduction of society. ${ }^{8}$ The obstacle to developing such a theory is the atomic structure of economics, in which tastes are simple, unanalyzed atoms.

The difference between atomic theories and circular theories, and the difference between rational and nonrational behavior, are obstacles to combining economics with sociology or social psychology, but there is a structural similarity which provides grounds for optimism. Social psychologists and sociologists are interested in the satisfaction of preferences. For example, there are countless surveys and experiments in which the satisfaction of the subjects is measured for different activities. To illustrate, social psychologists may approach the problem of justice experimentally by having subjects divide wealth in various ways and asking them which one they prefer. Or subjects may resolve disputes in various ways and then be asked which method gave them the most satisfaction. The economic model of man explains behavior as the rational satisfaction of preferences. So there is a similarity that could make the confluence of economics, social psychology, and sociology fertile.

\section{REFERENCES}

Arrow, K. J. (1951). Social Choice and Individual Values, 2nd ed., Yale University Press, New Haven.

Bentham, J. (1973). An Introduction to the Principles of Morals and Legislation, Hafner Press, New York, p. 3.

Bergson, A. (1938). A reformation of certain aspects of welfare economics. Quart J. Econ. 52. Blaugh, M. (1979). Economic Theory in Retrospect, 3rd ed., Cambridge University Press, Cambridge, MA.

Buchanan, J. The Limits of Liberty, Chicago, 1974.

Coase, R. (1967). The problem of social cost. J. Law Econ. 3: 1.

Cooter, R. (1983). Justice and mathematics: Two simple ideas. In Skurski, R. (ed.), New Directions in Economic Research, University of Notre Dame Press, Notre Dame, p. 198.

Cooter, R. (1978). Optimal tax schedules and rates: Mirrlees and Ramsey. Am. Econ. Rev. 68: 756.

Cooter, R., and Rappoport, P. (1984). Were the ordinalists wrong about welfare economics? J. Econ. Lit. 22: 507.

${ }^{8}$ There is a large economics literature on biological reproduction, as opposed to social reproduction. Indeed, to an outsider it appears that economic theory has largely taken over demography. There is as yet, however, no well-developed economic theory concerning, say, child-rearing. Economists sometimes describe the missing theory as a theory of "endogenous tastes" or as the theory of "household production functions." 
Cooter, R., and Ulen, T. (forthcoming). Law and Economics, Scott Foresman, Chicago. Dworkin, R. (1977). Taking Rights Seriously, Gerald Duckworth \& Co. Ltd., London. Hardin, R. (1987). Social justice in the large and small. Soc. Justice Res. 1: 83-106.

Jevons, W. S. (1871/1911). Theory of Political Economy, 4th ed., McMillan, London.

Mirrlees, J. A. (1971). An exploration in the theory of optimum income taxation. Rev. Econ. Stud. 38: 175 .

Musgrave, R. A., and Peacock, A. T. (1967). Classics in the Theory of Public Finance, St. Martin's Press, New York.

Nozick, R. (1974). Anarchy, State and Utopia, Basic Books, New York.

Pigou, A. C. (1920). The Economics of Welfare, 4th ed., MacMillan, London.

Posner, R. A. (1973). Economic justice and the economist. Public Interest 33: 109.

Posner, R. A. (1983). The Economics of Justice, Harvard University Press, Cambridge, MA.

Posner, R. A. (1986), The Economic Analysis of Law, 3rd ed. Little, Brown and Company, Boston.

Rawls, J. (1971). Theory of Justice, Belknap Press, Cambridge, MA.

Schumpeter, J. A. (1967). History of Economic Analysis, George Allen \& Unwin Ltd., London.

Sen, A. K. (1970). Collective Choice and Social Welfare, Holden-Day, Inc., San Francisco.

Shavell, S. (forthcoming). An Economic Analysis of Tort Law, Harvard University Press, Cambridge, MA.

Wittgenstein, L. (1961). Tractus Logico-Philosophicus, transl. by D. F. Pears and B. F. McGuinness, Routledge \& Kegan Paul, London. 